\section{The cannabis conundrum}

\author{
Philip Wiffen
}

There is no doubt that the medicinal use of cannabis and cannabinoids is controversial. While there are few licensed products, there are plenty of chronic pain patients and parents of children with treatment resistant epilepsy who are convinced that cannabis derivatives help these conditions. These sufferers often source the product outside the law at huge expense and lobby politicians and senior decision-makers to fight for increased availability. Pharmacists will be aware that many substances can be extracted from the cannabis plants, but two important ones are tetrahydrocannabinol (THC) and cannabidiol (CBD). THC is one of the psychoactive components.

Until late 2018, WHO took the view that cannabis and its derivatives had no medicinal value and were seen only a substance of misuse, ${ }^{1}$ at long last evidence has impacted what was essentially a political decision and WHO seem more open to consider the medicinal value. In November 2019, the National Institute for Health and Care excellence (NICE) in the UK issued initial guidance ${ }^{2}$ on the use of cannabis and cannabinoids across a range of conditions. There are those who welcome these changes and others who argue that they don't go far enough. So what has NICE recommended? The following conditions are discussed:

Intractable nause and vomiting. Nabilone is suggested as an add-on (for over 18-year-olds) for chemotherapy-induced

Correspondence to Professor Philip Wiffen, Pain Research Unit, Churchill Hospital, Oxford OX3 7LE, UK; pwiffen@oxfordsrs.org.uk nausea and vomiting that persists despite conventional antiemetics.

Spasticity in adults with multiple sclerosis. NICE suggests offering a 4-week trial of THC:CBD spray to treat moderate to severe spasticity under certain conditions. These include showing that current treatments have not been effective and that following a 4-week trial, THC:CBD spray should only be continued if the user has had at least a $20 \%$ reduction in spasticityrelated symptoms on a 0 to 10 patientreported numeric rating scale. Treatment can only be initiated by a specialist.

Severe treatment-resistant epilepsy. NICE declined to go further than make recommendations for further research. While there is a strong lobby for cannabis products to be made available for this condition and some anecdotal evidence, there is little in the way of reliable evidence.

Chronic pain in children and adults. NICE also declined to make recommendations here also again making recommendations for research in fibromyalgia and neuropathic pains. They did recognise that there was some evidence to show that $\mathrm{CBD}$ reduces chronic pain, but the treatment effect is modest. NICE have published their evidence review on its website.

As someone who has worked in evidence-based pain medicine for a number of years, I do understand the dilemma. We are currently in the bizarre situation where the number of systematic reviews for cannabis products for pain relief are greater than the number of clinical trials. Many of the systematic reviews suffer from poor methodology and so are unreliable. This poor understanding of the science and evidence of benefit often generates more heat than light and there are strongly held views among pain specialists on both sides of the argument.

We certainly need more evidence, but who will organise and deliver these trials given the issues around the chemistry of cannabinoids and the legal restrictions?

There is no doubt that the cannabis story has a way to run and is likely to remain controversial for the foreseeable future. Sadly, there may well be sufferers from serious conditions who cannot access potentially helpful derivatives because the evidence doesn't exist. Do the benefits outweigh the harms? We just don't know.

\section{Competing interests None declared.}

Provenance and peer review Commissioned; internally peer reviewed.

(c) European Association of Hospital Pharmacists 2020. No commercial re-use. See rights and permissions. Published by BMJ.

$$
\text { A) Check for updates }
$$

To cite Wiffen P. Eur J Hosp Pharm 2020;27:1. Published Online First 26 November 2019

Eur J Hosp Pharm 2020;27:1.

doi:10.1136/ejhpharm-2019-002154

\section{ORCID iD}

Philip Wiffen http://orcid.org/0000-0001-6085-1307

\section{REFERENCES}

1 WHO news. WHO endorses decisions of Expert Committee on cannabis and other substances. Available: https://www.who.int/medicines/news/2019/ecddendorses-decisions-ECDD_cannabis-other-substance/en/ [Accessed Nov 2019].

2 NICE. NICE guidance on cannabis based medicinal products. Available: https://www.nice.org.uk/guidance/ ng144 [Accessed Nov 2019]. 